Mirai. Estudios Japoneses

ISSN-e: 2531-145X

https://dx.doi.org/10.5209/mira.74017

\title{
Fuentes sobre el origen del concepto de 'otaku'
}

\author{
Jorge Rodríguez Cruz ${ }^{1}$ (iD
}

Recepción: 30/01/2021 / Aceptación: 09/04/202

Resumen. El proceso de asociación del concepto de 'otaku' con la imagen estereotipada que la sociedad japonesa ya tenía de ese grupo, o lo que es lo mismo, la génesis de la definición actual del término, se desarrolló a lo largo de los años ochenta del siglo XX hasta que terminó popularizándose a finales de la década, gracias al infame "incidente Miyazaki”. Dos artículos publicados en revistas dedicadas a fans del anime a principios de esa década resultan clave para la comprensión de este proceso: por un lado, la definición que Shirakawa Shōmei hizo en 1981, como parte de una guía para nuevos estudiantes, de aquellos jóvenes que pertenecían a los clubs de cultura escolares; y por otro, el reconocido como primer texto que acuña el término 'otaku' en asociación a una imagen similar a la ofrecida por Shirakawa, el artículo publicado en tres partes en el verano de 1983 por Nakamori Akio. En este trabajo se presenta una traducción inédita al español realizada directamente desde los textos originales, así como un análisis sobre la relevancia de estos.

Palabras clave: otaku; Nakamori Akio; Shirakawa Shōmei; manga; historia conceptual; textos.

\section{[en] Sources on the origin of the concept of 'otaku'.}

\begin{abstract}
The process of associating the concept of 'otaku' with the stereotyped image that Japanese society already had of that group or, in other words, the genesis of the current definition of the term, developed throughout the 1980s until it became popular at the end of the decade, thanks to the infamous "Miyazaki incident". Two articles published in magazines dedicated to anime fans at the beginning of that decade are key to the understanding of this process. On the one hand, the definition of those young people who belonged to school culture clubs that Shirakawa Shōmei made in 1981 as part of a guide for new students; and on the other, the text that is recognized as the first to coin the term 'otaku' in association with an image similar to that offered by Shirakawa: the article published in two parts in the summer of 1983 by Nakamori Akio. This paper presents a so far unpublished translation into Spanish made directly from the original texts, as well as a brief review of their authors and an analysis of their relevance.
\end{abstract}

Keywords: otaku; Nakamori Akio; Shirakawa Shōmei; conceptual history; manga; texts.

Sumario: 1. Introducción; 2. Contextualización histórica; 3. El texto de Shirakawa Shōmei, 3.1. Comentario; 4. Los artículos de Nakamori Akio, 4.1. Comentario; 5. Conclusión.

Cómo citar: Rodríguez Cruz, J. Fuentes sobre el origen del concepto de 'otaku’, en Mirai. Estudios Japoneses, 5, 2021, $127-134$.

\section{Introducción}

El término 'otaku' se ha hecho muy popular en las últimas décadas, y se ha asociado globalmente con los aficionados al manga y el anime y con sus actividades, provocando una desnaturalización de su significado original. ${ }^{2}$ En Japón, hablar de 'otaku' conlleva una serie de matices con una carga peyorativa que nos indican tanto la inicial intención discriminatoria de esta etiqueta como la pervivencia de esa idea en la sociedad.

Para comprender mejor estos matices, debemos estudiar la construcción de la misma etiqueta 'otaku', un proceso al que se le puede seguir el rastro desde finales de los años setenta y principios de los ochenta del siglo XX, hasta finales de esa década, cuando el concepto saltó de forma masiva a los medios de comunicación, popularizándose y asentando entre la sociedad tanto su uso como su significado a raíz del "incidente Miyazaki".

Doctorando en Filología Moderna en la Universidad de Salamanca y pertenece al Grupo de Investigación Reconocido "Humanismo Eurasia"

E-mail: jorgerodcr@gmail.com

ORCID: https://orcid.org/0000-0003-0824-6526

Estas traducciones forman parte del desarrollo de su tesis doctoral en el seno de dicho grupo.

2 El uso tradicional de ‘otaku’ se escribe en japonés con kanji, お宅, y corresponde a un lenguaje honorífico o respetuoso (sonkeigo), según el diccionario Jisho. Puede ser tanto un nombre que se traduce como "tu casa, tu familia" (la traducción más habitual, aunque también puede traducirse como "tu marido" o "tu organización"), como un pronombre de segunda persona utilizado para referirse a una persona de estatus similar a la que no se es especialmente cercano.

Mirai. Estud. Japon. 5, 2021: 127-134 
Este incidente hace referencia a los asesinatos cometidos por Miyazaki Tsutomu, ${ }^{3}$ también conocido como "el asesino otaku", quien terminó con la vida de cuatro niñas pequeñas en los alrededores de Tokio entre 1988 y 1989. Cuando fue detenido, la policía registró su habitación y encontró miles de cintas VHS con anime de género gore, pornografía violenta o incluso una importante cantidad de pornografía infantil. Esa información permitió a la prensa construir una imagen del asesino, relacionando sus parafilias sexuales con sus aficiones. A modo de ejemplo, Morikawa Kaichirō recoge varios titulares del periódico Asahi Shinbun, en ediciones de agosto de 1989, que expresan esta relación de forma muy ilustrativa: "La perversión se esconde en la soledad" o "¿Sus compañeros? Anime y vídeos". ${ }^{4}$

Dentro del proceso de elaboración del término 'otaku', gozan de una importancia clave los artículos publicados en 1983 por el ensayista Nakamori Akio, pues se ha aceptado de forma unánime que se trata de los primeros textos en que se utiliza 'otaku' con el significado que tiene actualmente, y en los que se ofrece una amplia definición de este. El Estudio de 'otaku'(『おたく』の研究) $)^{5}$ realizado por Nakamori es, de hecho, imprescindible para comprender el trato que los medios darían años más tarde al término tras el "incidente Miyazaki”, pues su 'otaku' sería utilizado por la prensa para definir a Tsutomu Miyazaki, relacionando así la imagen del asesino con este término.

Por otra parte, es especialmente interesante para entender el contexto en el que Nakamori Akio escribió sus ensayos, el extracto de otro artículo publicado dos años antes por Shirakawa Shōmei, ${ }^{6}$ quien ofrece una descripción de los miembros de los clubs de cultura y aficionados al manga y la ciencia ficción. Este texto, que puede considerarse como un verdadero precedente, coincide en gran medida con las características expuestas por Nakamori, permitiendo así rastrear la existencia previa de una imagen semejante a la que construiría ese autor al acuñar el término 'otaku'.

Aunque ambos textos son bastante conocidos en el ámbito de los estudios otaku en Japón, siendo los artículos de Nakamori reconocidos más allá de las fronteras niponas, lo que les hace contar con traducciones al inglés, lo cierto es que, más allá de referencias puntuales y de alguna traducción parcial no académica, y a pesar de la relevancia que tienen, son textos que prácticamente no han sido estudiados en el contexto de la investigación en habla hispana. Es por eso por lo que considero de gran importancia la publicación de una traducción al castellano de ambas fuentes, con el objetivo de facilitar su acceso a los investigadores que quieran comprender mejor el origen del término 'otaku'.

En este trabajo, por tanto, se presenta de forma inédita la traducción al castellano tanto del extracto del ensayo de Shirakawa Shōmei, como del texto íntegro de los tres breves artículos de Nakamori Akio. La traducción ha sido realizada directamente desde la fuente original en japonés, supervisada por los Seminarios de Traducción de la Sección de Estudios Japoneses, que es parte del Ârea de Estudios de Asia Oriental del Departamento de Filología Moderna de la Universidad de Salamanca, y que están dirigidos por el Profesor Alfonso Falero, en un periodo comprendido entre mediados de 2018 y mediados de 2019, y corregida y revisada por hablantes nativos japoneses.

\section{Contextualización histórica}

Aun con dos años de diferencia, tanto el texto de Shirakawa como los tres artículos de Nakamori pueden situarse dentro del final de una etapa de transición dentro de la historia del manga-anime y de sus aficionados en Japón.

Desde la segunda mitad de la década de 1970, el estereotipo de geek japonés cuyas características principales fueron definidas por Shirakawa en 1981, hacía referencia sobre todo a los aficionados de la ciencia ficción, y no tanto a los aficionados al anime o el manga. Solo a finales de la década y a raíz del éxito de series de anime como Space Battleship Yamato (Uchū Senkan Yamato, Matsumoto Reiji, 1974-75), Mobile Suit Gundam (Kidō Senshi Gandamu, Tomino Yoshiyuki, 1979-80) o Macross (Kawamori Shōji, 1982-83), obras que pueden situarse dentro del género de la ciencia ficción, estos aficionados comenzaron a interesarse masivamente por

Para la mención de los nombres propios en este texto, se ha optado por mantener la costumbre japonesa de situar el apellido antes que el nombre. Por tanto, en este caso, Miyazaki corresponde al apellido y Tsutomu al nombre de pila.

4 Morikawa, Kaichirō and Dennis Washburn. “おたく/Otaku/Geek”, Working Words: New Approaches to Japanese Studies, University of Berkeley (2012): 8 .

Nakamori, Akio. “Otaku’ no kenkyū - (1) Machi ni wa ‘otaku’ ga ippai” (『おたく』の研究 - (1) 街には『おたく』がいっぱい), Manga Burikko (漫画ブリッコ), no junio (1983): 200-201; Nakamori, Akio. “'Otaku’ no kenkyū - (2) ‘Otaku’ mo hitonami ni koi o suru” (『おたく』 の研究 - (2 ) 『おたく』も人並みに恋をする?), Manga Burikko (漫画ブリッコ), no julio (1983): 89-100; y Nakamori, Akio. “'Otaku’ no kenkyū - Otaku chitai ni mayoikonda de” (『おたく』の研究 - おたく地帯に迷いこんだで), Manga Burikko (漫画ブリッコ), nªgosto (1983), consultado el 18-04-2021, http://www.burikko.net/people/otaku03.html.

$6 \quad$ Shirakawa, Shōmei. "Darakukun no yoiko kyōshitsu koyoi mo kamonoha shiru dai 1 kai: shin'nyūsei no tame no hissatsu yoi ko kokoroe shūtoku kōza” (「ダラク君のよい子教室今宵も力モノ八しる第 1 回 : 新入生のための必殺よい子心得習得講座」), Fanrōdo 2, no. 2 (ふあんろ ーど第 2 巻第 2 号) (1981), pp. 68-71. 
ese medio y, en consecuencia, por el manga, según las afirmaciones tanto de Morikawa ${ }^{7}$ como de Okada Toshio. ${ }^{8}$

Este incremento en el número de aficionados al manga y al anime puede comprobarse ya a lo largo de los años setenta, con un crecimiento en las ventas por año de unidades vendidas de revistas de manga, que pasaron de los apenas 400 millones en 1969, a alrededor de 900 en $1979,{ }^{9}$ y que terminará disparándose en la primera mitad de la década de los ochenta. En concreto, en 1983, el año en que Nakamori Akio publicó sus artículos, las ventas semanales de las revistas de mayor tirada oscilaban entre los 2 millones de Magazine y los 3 millones de Jump,${ }^{10}$ aunque el momento de mayor auge del mercado no llegaría hasta mediados de los años noventa, con cifras de hasta 6.53 millones de unidades semanales vendidas alcanzadas por la revista Jump. ${ }^{11}$ Más tarde, con el cambio de milenio y, sobre todo, con la irrupción de la piratería a través de Internet, las ventas se estancarían e iniciarían un prolongado retroceso que ha continuado hasta la actualidad.

Esta situación de la industria del manga dibuja la década de 1980 como una etapa de pleno crecimiento, un hecho que se ve claramente reflejado en el constante éxito de las sucesivas ediciones del Comic Market o, abreviado, ComiKet. El ComiKet surgió como una convención, al estilo de la Comic Con de San Diego, creada por varios jóvenes críticos de manga que buscaban un lugar en que pudiera venderse y comprarse el manga de factura amateur, el dōjinshi, realizado al margen de una industria cada vez más estandarizada y controlada por las grandes editoriales, que en los años setenta comenzaron a dejar de lado los contenidos de corte político o irreverente y se centraron en géneros más comerciales. ${ }^{12}$

Aunque las primeras ediciones contabilizaron una asistencia más bien reducida, a medida que se incrementaba el mencionado interés de los aficionados de la ciencia ficción por el anime, las cifras de asistentes al ComiKet comenzaron a crecer de forma exponencia ${ }^{13}$ desde los 600 asistentes en la primera edición, celebrada en 1975, hasta los casi 15.000 en 1983, llegando a alcanzar la incré́ble cifra de 250.000 asistentes en el año $1990 .{ }^{14}$

La etapa comprendida entre la publicación del ensayo de Shirakawa en 1981, y la publicación de los tres ensayos de Nakamori en junio, julio y agosto de 1983, responde al periodo en que los aficionados de la ciencia ficción están empezando a asentarse como dominantes entre los aficionados al anime y el manga, siendo los principales artífices de su éxito comercial y, en definitiva, poniendo en relación el consumo del anime con el estereotipo del geek. Es decir, la etiqueta de 'otaku' no reflejará a los que eran los aficionados originales al anime, sino a estos nuevos aficionados cuyas aficiones y características darán forma a la atmósfera descrita por Nakamori.

Morikawa señala que la discriminación hacia los 'otaku' no se produjo por el hecho de que vieran anime, sino que el anime comenzó a ser visto como algo propio de los geeks, ${ }^{15}$ y la propia influencia de estos 'otaku' se reflejará en el devenir posterior de la industria del anime y, en consecuencia, del manga y los videojuegos.

\section{El texto de Shirakawa Shōmei}

En 1981, el ensayista Shirakawa Shōmei publicó un artículo en la revista para fans del anime Fanrōdo, ${ }^{16}$ en que describía los diferentes tipos de alumnos que un nuevo estudiante se encontraría al entrar en una típica escuela de secundaria de esa época (no en vano, hemos traducido el título general de todo el texto como Catálogo de la clase de buenos chicos de Daraku-kun). ${ }^{17}$ Sin embargo, es la breve descripción que hace de los miembros de los clubs de cultura, un apartado (2. "Club de cultura") dentro de la sección referente a los clubs escolares ("i¿Qué es un club?!"), la que resulta realmente interesante como precedente y contextualización de la definición dada por Nakamori Akio dos años más tarde. A continuación, se expone la traducción íntegra de ese apartado.

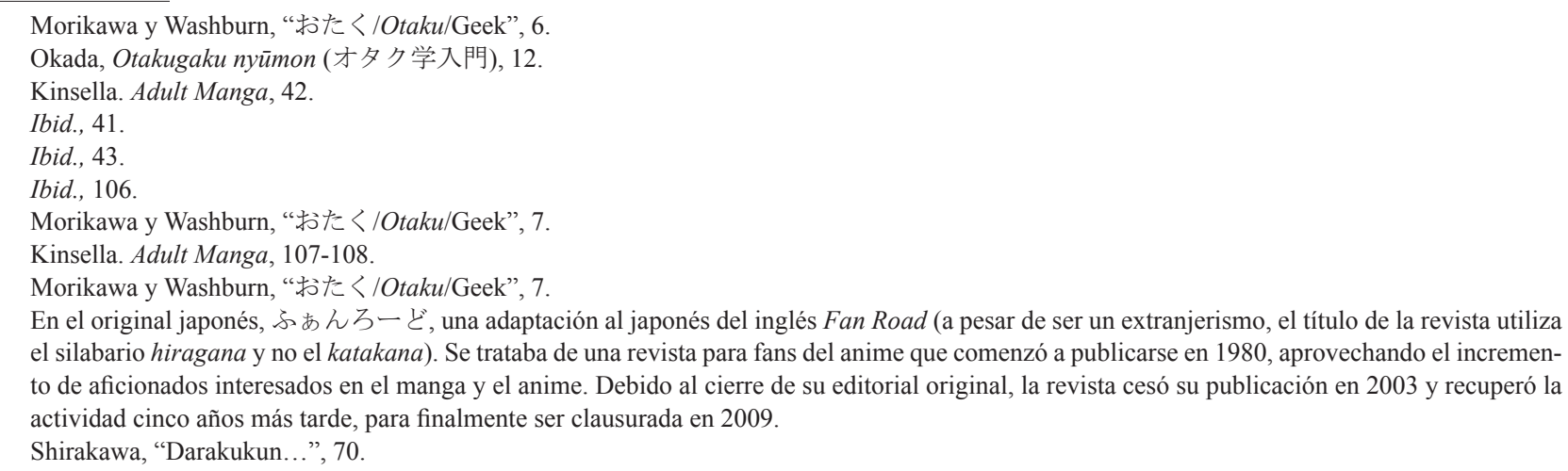




\author{
Catálogo de la clase de buenos chicos de Daraku-kun \\ (Shirakawa Shōmei) \\ N. ${ }^{0} 1$ - Curso para ponerse al día: cómo ser buen chico a muerte para novatos \\ 1. ¿¿Qué es un club?! \\ 2. Club de cultura
}

\begin{abstract}
Los llamados clubs de cultura son una agrupación del tipo de chicos obōchan lerdos, que son lentos en sus movimientos y son plastas, y en conjunto, digamos que parecen como gorditos; en resumen, en este grupo muchos de los chicos son obesos. Como no son buenos para el ejercicio físico, determinan que el ejercicio físico en sí mismo es malo y hablan de ese tipo de actividad como si les fuera la vida en ello, como algo sin significado, y van a muerte con ello; riéndose del ejercicio físico, de alguna manera están inmersos en un sentido de superioridad de carácter autocomplaciente (piensan de sí mismos que son la caña). También, el hecho de hacer cosas en plan secreto, cuchicheando en el grupito, es característico de los clubs de cultura, pero la realidad es que no hacen nada de importancia. Además, son superexpertos sobre su propio tema de interés, pero solo saben de eso. Por ejemplo, en la naturaleza de este libro, tomando como muestra los grupos de estudio del manga en los clubs de cultura y ciencia ficción, la música que escuchan los que están en estos grupos, son, en su mayoría, o temas musicales de anime o bandas sonoras de películas de ciencia ficción, y la música del tipo que escuchan los jovenzuelos en general, forzadamente la ignoran de forma ostentosa para mantener la pose. ${ }^{18}$
\end{abstract}

\title{
3.1. Comentario
}

Una lectura del texto de Shirakawa permite comprobar que posee una importante carga irónica y caricaturesca, pero refleja, como señala Morikawa, ${ }^{19}$ la jerarquización de la sociedad escolar de la época en función de sus capacidades físicas. Los clubs de cultura debían de ser una vía de escape para todos aquellos que no tenían grandes capacidades atléticas y que eran marginados por ello, un lugar donde podían compartir otro tipo de aficiones o criticar como inferiores a ellos a los que sí eran buenos en los deportes. Estas características físicas son definitorias del estereotipo del nerd incluso fuera de Japón, y son elementos que podrán encontrarse también en los artículos de Nakamori.

Aunque lo trata como una característica secundaria, lo cierto es que el segundo elemento que Shirakawa remarca en su texto es el conocimiento obsesivo de estos jóvenes tanto del manga y el anime como de la ciencia ficción, situando ya ambos medios como intereses paralelos sin predominancia de ninguno de ellos. En 1981, año de publicación del artículo, el previamente mencionado éxito del anime provocado por el estreno de obras como Space Battleship Yamato o Mobile Suit Gundam ya se había producido, y aquellos fans de la ciencia ficción que cargaban con las características propias del nerd, habían comenzado ya a mostrar interés también por el manga y el anime.

Al tratarse únicamente de una parte mínima dentro de una catalogación más amplia, la descripción que hace Shirakawa no profundiza más en las características de este grupo y dibuja una idea más bien vaga sobre él. Sin embargo, la relevancia de su texto surge un par de años más tarde, cuando la descripción propuesta de Nakamori para 'otaku' utiliza de nuevo las características básicas que Shirakawa adjudica a los miembros de los clubs de cultura escolares, lo que permite confirmar tanto la existencia previa a la acuñación de 'otaku' de un estereotipo peyorativo que hace referencia a estos jóvenes, como comprobar, en comparación, un estado más inicial del progresivo interés de los nerds de la ciencia ficción por el anime y el manga.

En conclusión, se puede afirmar que el texto de Shirakawa Shōmei es de gran interés para comprender mejor, a modo de precedente, los famosos artículos que Nakamori Akio publicará dos años más tarde.

\section{Los artículos de Nakamori Akio}

Dos años después de la publicación en Fanrōdo del ensayo de Shirakawa Shōmei, sería Nakamori Akio el encargado de recoger el testigo y, finalmente, otorgar un nombre a esa idea preexistente. El título común de los tres artículos, publicados a modo de columna de opinión en los números de junio, julio y agosto de 1983 de otra revista para fans del anime llamada Manga Burikko ${ }^{20}$, de la que entonces Ötsuka Eiji era editor, es Estudio de 'otaku'21 , si bien su importancia no se basa en su calidad académica o en la falta de ella, sino en ser el primer texto en utilizar 'otaku' como término definitorio de esa idea ya expuesta por Shirakawa, ampliando de forma

\footnotetext{
Shirakawa, "Darakukun...", 70

Morikawa y Washburn, “おたく/Otaku/Geek”, 5.

En el original japonés, 漫画ブリッコ. Se trataba de una revista para fans del anime y el manga, dedicada concretamente al manga erótico de género lolicon hentai (a modo de definición, puede decirse que lolicon hace referencia a un género de manga y anime destinado a hombres protagonizado por chicas atractivas menores de edad en situaciones sexualizadas (Kamm (2015): 65)). Fue publicada entre noviembre de 1982 y febrero de 1986 por la editorial Byakuya Shobō.

21 Nakamori. “'Otaku’ no kenkyū - (1)"; Nakamori. “'Otaku’ no kenkyū - (2)”; y Nakamori. “'Otaku’ no kenkyū - otaku”.
} 
considerable su descripción. Es, por tanto, un texto clave para la comprensión tanto de la realidad de los otaku en esa época como de la imagen que la sociedad tendría de ellos desde entonces y, sobre todo, imprescindible para conocer el origen formal del término 'otaku'22.

\section{Estudio de 'otaku'}

(Nakamori Akio)

\section{(1) La ciudad está llena de 'otaku' (Número de junio de 1983)}

¿Conoces el ComiKet (abreviado ComiKe)? Bueno, yo también fui por primera vez el año pasado con 23 años, pero me quedé flipado. Quiero decir, esto, en otras palabras, parece un festival para la manga manía, y una feria de, en pocas palabras, dōjinshi de manga y fanzines. Si me preguntas qué me sorprendió, en fin, pues que se vienen reuniendo más de 10.000 chicos y chicas del interior de Tokio y, sin embargo, qué frikis son. Me pregunto qué dicen, en todas las clases están esos tipos que son unos verdaderos inútiles en el ejercicio físico, que se divierten jugando en la sombra a cosas como el shogi, ${ }^{23}$ aislados dentro del aula durante los descansos. Es que eran así. El corte de pelo a lo tazón al estilo Botchan, que da miedo. Vienen tambaleándose y llenando su ya abultada mochila, vistiendo estilosamente camisetas y pantalones de precio estándar $980 ¥$ y $1980 ¥$ que les ha comprado su mamá en Itō Yōkadō o Seiyu, con unas zapatillas de deporte sneakers de imitación legal de la marca R pasadas de moda, esos tíos son. Entonces, como si los nutrientes no les terminaran de llegar a esos esmirriados, parecen como cerdos pálidos que sonríen con las patillas de sus gafas de montura plateada embutidas en la frente; mientras que las mujeres son en su mayoría okappa que en general engordan y esconden sus piernas gruesas como troncos en calcetines blancos, de modo que parecen columnas. Normalmente están en un rincón de la clase, sin llamar la atención y con los ojos como muertos, y tampoco tienen ni un amigo; esa gente, sin embargo..., hasta me da vueltas la cabeza, ¡de dónde han salido en bloque 10.000 personas así! Habitualmente también es gente muy oscura, pero dentro de su mundo parecen estar muy contentos. Tíos que imitan la ropa de un personaje de anime; tíos con el estilo oscuro de ese manga... ya sabes, de Azuma; tíos pesados que se empeñan en vender fanzines de lolicon a niñas; tíos que corretean alrededor sin razón aparente... uf, me iba a estallar la cabeza. Generalmente, son niños y niñas que se encuentran entre los estudiantes de secundaria de 10 a 20 años, ¿no?

Ahora que lo pienso, no se reduce solo a los fans del manga o del ComiKe: tíos que esperan en la cola, desde la víspera del estreno de las películas de anime; tíos que están a punto de morir atropellados en la vía férrea por fotografiar el tren azul con esa cámara de la que están tan orgullosos; tíos que a lo largo de la estantería amontonan números atrasados de mangas de ciencia ficción y la serie de ciencia ficción de lomo dorado o plateado de Hayakawa; chicos de ciencias con gafas de culo de botella que se reúnen en tiendas de microcomputadores; tíos que guardan el sitio yendo temprano a las sesiones de firmas de $i d o l^{24} \mathrm{y}$ talent ${ }^{25}$ esos tíos que flipan con el audio, que con maneras de pijo tembloroso se vuelven bobos con ojos de sardina que estudian en academias únicamente para pasar de nivel de estudios. Entonces, estamos hablando de gente a la que normalmente llamamos maniáticos o fanáticos, o a lo sumo, a los que pertenecen a la tribu nekura ${ }^{26}$ pero no hay manera de encajarlos. Me parece que no se ha establecido un nombre preciso que integre el conjunto del fenómeno de esta gente, aunque es por eso que nosotros... bueno, tienen algo por lo que hemos decidido llamarlos 'otaku', así que he optado por llamarlos así a partir de ahora.

A asuntos como por qué fueron llamados 'otaku' o a la pregunta sobre qué es otaku, déjenme responder en serio y con tiempo la próxima vez, pero, de alguna u otra forma, puedes notarlo, por favor, intenta echar un vistazo

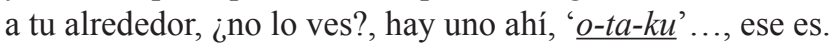

Por cierto, otaku, pero ¿qué es 'otaku'?27

\section{(2) ¿Los 'otaku' también se enamoran de gente normal? (Número de julio de 1983)}

De esta forma, la vez anterior planteé llamar 'otaku' a los decadentes grupos de chicos nekura, tan comunes en estos días. En cuanto al origen de la palabra 'otaku', bueno, creo que todos estaréis de acuerdo, pero no pienso que sea estúpido, por ejemplo, que un mocoso se esté dirigiendo a sus amigos con una expresión así como "vosotros, otaku" en el ComiKe o en convenciones de anime.

\footnotetext{
Entendido como sinónimo de nerd.

El shōgi, también conocido como ajedrez japonés, es un juego de estrategia tradicional para dos jugadores.

アイドル (aidoru) es una adaptación directa al japonés del inglés idol. Hace referencia a jóvenes celebridades de Japón, que van desde la adolescencia hasta poco más de 20 años, que han conseguido gran fama gracias a la publicidad. Tanto chicas como chicos, son sobre todo cantantes y actores.

25 タレント (tarento) es una adaptación directa al japonés del inglés talent. Hace referencia a los famosos que aparecen frecuentemente en los medios de comunicación de Japón.

26 En referencia a la forma de ser de una persona, significa que tiene una "raíz oscura". Antes de la popularización del término 'otaku' y compartiendo su matiz peyorativo, nekura era utilizado para referirse a aquellos jóvenes introvertidos y poco sociables que preferían los hobbies solitarios.

27 Nakamori. “'Otaku’ no kenkyū - (1)”, 200-201.
} 
Pues eso, como no dejan de ser hombres, debido a la pubertad están despertando, entre otras cosas, su lascivia. Pero ese estilo, ese habla, esa personalidad... así no pueden llegar a tener novia. Entonces, 'otaku' significa definitivamente que desaparece la masculinidad. Poniendo en su tarjetero del tren imágenes de personajes de anime como, normalmente, Minky Momo ${ }^{28}$ o Nanako, ${ }^{29}$ sin embargo... bueno, vamos a llamarlo complejo 2D, el caso es que tampoco son capaces de hablar con una mujer real. Esta es la razón de ir a ver a una cantante idol que no llama demasiado la atención del público femenino y que, por otro lado, está un poco desviada hacia el lolicon. Eso es por lo que no soportan algo así como la fotografía de una mujer adulta desnuda. Un hombre que yo conozco, sin embargo, aunque alguien intente mostrarle amablemente una revista porno, este tío desvía la mirada frenéticamente mientras grita “¿Quita! ¡Qué asco!”; pues bueno, esa clase de tío es el que está editando ahora "Comic Box". ${ }^{30}$

Y la única cosa que yo tolero de ese tipo de gente es la fotografía realista de Kishin ${ }^{31}$ que se publica en esa revista otaku, Goro. ${ }^{32}$ Por ejemplo, que la revista invita a enviar cartas a Kumiko-kun, pues ella responde a la correspondencia que le envían. Horroriza también solo de pensarlo, pero cuántas decenas de miles de cartas de 'otaku' estarán recibiendo en el departamento editorial. Ese que se va hasta la tienda de libros de la ciudad vecina esperando con impaciencia el lanzamiento de las fotografías, que recorta las de la chica que le gusta y las archiva (aquí en esto también es muy otaku), que tiene 26 años y es empleado y cuando su mujer le descubre dice “¡Joder, la he cagado!”; los hay que componen poesía y la envían a la chica de turno; así de tontos son, tanto que me da dolor de cabeza. Pero es que los hay, y también está el tío que almacena en la estantería del sucio alojamiento de cuatro tatamis y medio, sin una doblez y sin que falte ni uno, los últimos números de Goro. Entre estos, los hay que compran al mismo tiempo dos volúmenes del mismo número, uno para guardarlo y otro para lo que sea.

Aparte de eso, resultan un poco maricas, quizá porque están perdiendo la masculinidad. Es ese adulto que ha superado los 20 años, que hace cosas como, al haber conseguido el póster de su personaje de anime favorito, flexionar las piernas en forma de L con ambas rodillas juntas exclamando "guau" de la alegría, y pega un salto haciendo boing (ese "salto y flexión en forma de L de ambas piernas" es una increíble característica de ellos); cuando da ese salto tan torpe, yo pienso "que lamentable" y me dan ganas de llorar; realmente me da mal rollo. Generalmente, la conclusión es que no pueden existir mujeres para ese tipo de tíos.

Pero, a pesar de ello, todo el mundo se acaba casando. Entonces, me resultaba curioso desde hace mucho tiempo lo de con quién se casa el otaku, aunque me di cuenta de algo horripilante. Resultó que los 'otaku' se casan con "mujeres otaku” y tienen "niños otaku”... Tachán..$^{33}$

\section{Perdido en la zona otaku (Número de agosto de 1983)}

Hola a todos, ¿vais de otaku? La palabra 'otaku' se ha asentado de forma extraordinaria, creo que es momento de quitarle las comillas. Por eso, a partir de ahora no se puede afirmar en todos los casos, pero cuando usamos otaku, ya no es un pronombre personal de segunda persona, sino un nombre común. Otaku a veces se usa como "otakuppoi" u "otakuru", ${ }^{4}$ como adjetivo o como verbo. Usadlo según convenga en cada caso. Cuando descubrí la palabra 'otaku', nadie sabía lo que significaba, me permití el lujo de juguetear con ella. Han puesto una librería de dojjinshi de manga llamada Free Space en el distrito 3 de Shinjuku, y eso es lo que lo hace un lugar de reunión para los otaku. Cuando fui ahí acompañado de mi novia de segundo de bachiller, Yumi, dije "mira, otaku por ahí, otaku por allá, ese tío es súper otaku”, definitivamente llamaba otaku a los otaku. Los tíos estos no entendían lo que quería decir, así que se sentían aturdidos y ponían ojos de "Oshin", ${ }^{35}$ mirándonos con perplejidad. Entonces Yumi, desternillándose y con la cara roja como un tomate dijo "jajaja, para ya, Akio". * En una zona de Free Space que está separada por lo que parece un umbral, tienen como una cafetería, y desde dentro se escuchan risas raras. Creo que solo los que escuchan aquello lo entienden, pero son como risas perturbadoras, como si hubiera un grito para las babosas o las sanguijuelas, probablemente fuera ese. Es una risa tremendamente inquietante. Pensando qué sería, Yumi echó un vistazo desde el otro lado del umbral y exclamó "iiih" de golpe, echándose hacia atrás en un acto reflejo, se puso a temblar. Me pregunté qué pasaba, eché un vistazo y lo entendí: me encontré con que había 7 u 8 gusanos que entre los otaku parecían todavía más otaku. Con revistas de anime y pósteres esparcidos sobre una mesa, y haciendo bromas que solo ellos pueden

\footnotetext{
Personaje protagonista de la serie de anime “魔法のプリンセス ミンキー モモ” (Mahō no purinsesu minkīmomo, 'La Princesa Mágica Minky Momo'), emitida en Japón entre 1982 y 1983.

29 Personaje protagonista de la serie de anime “ななこSOS” (Nanako esuouesu, 'Nanako SOS’) emitida en Japón entre 1980 y 1986, basada en el manga original de Azuma Hideo, autor fallecido el 13 de octubre de 2019.

Revista de información sobre manga que comenzó a publicarse en Japón en 1982.

Shinoyama Kishin es un fotógrafo nacido en Tokio que se especializó en fotografía de desnudo artístico.

Revista para hombres de la editorial Shōgakukan que se publicaba dos veces al mes desde 1974 hasta 1992, con contenido variado.

Nakamori. "'Otaku' no kenkyū - (2)", 89-100.

おたくつぽい (otakuppoi) puede traducirse “como otaku”, y おたくる (otakuru) puede traducirse como "ser otaku”.

Oshin es una serie de drama japonés matutina que se emitió en la cadena NHK entre el 4 de abril de 1983 y el 31 de marzo de 1984 . La serie sigue la vida de Tanokura Shin desde el periodo Meiji hasta la década de 1980. Shin se llamaba “Oshin”, que es un cognomen arcaico japonés. La serie constó de un total de 297 episodios de 15 minutos.
} 
entender, se partían de la risa en su círculo de colegas. Es como si fuera un aquelarre del infierno, una escena repugnante. Como si fuera la final de una convención otaku nacional en el área de Kanto. Yo mismo me puse a temblar de miedo. También Yumi estaba temblando, parecía como si tuviera pesadillas y le salió urticaria. Pensando de dónde habrán surgido seres como esos, se sentía muy enfadada.

Después de eso, de acuerdo con lo que me dijo alguien que sabe sobre los otaku que van a Free Space, ellos suelen reunirse allí en enjambres casi todos los días, llueva o truene. * Parece que, como pasan allí tanto tiempo, ponen un aviso cuando se van durante más de dos horas. Dice que, al principio, él pensaba que eran unos tipos repugnantes, pero después empezó a mostrar empatía por los otaku, y dijo "ellos solo pueden venir aquí, y por separado son tranquilos y majetes". Con relación a esto, me pareció raro, pero ellos siguen y siguen reuniéndose todos los días al terminar la escuela y, sin embargo, me pregunto dónde pasaban el rato antes de que abrieran Free Space. Según él, “Ah, hasta entonces ellos estaban cada uno por su lado”.

Salimos de Free Space para que Yumi se calmara y escapamos al Shinjuku Gyōen ${ }^{36}$. Mientras abrazaba a Yumi en el césped del parque, me acordaba de esa pandilla de otaku de hace un momento y me reía. Poco después del mediodía, el distrito 3 de Shinjuku es un lugar extraño: una pareja flirteando en el parque, un otaku de ojos oscuros con chaqueta de safari dirigiéndose a Free Space, maricas tempraneros caminando por ahí... ${ }^{37}$

\subsection{Comentario}

La relevancia que tienen los tres artículos escritos por Nakamori Akio en 1983 recae, por un lado, en el hecho de que sean considerados los primeros textos publicados en que se usa el concepto 'otaku', y por otro, en la popularización y generalización de su definición. Sin embargo, tal importancia no debió de empezar a ser tenida en cuenta sino hasta finales de la década de 1980 o principios de los años 90, cuando la prensa utilizó 'otaku' para describir a Miyazaki Tsutomu, el "asesino otaku". De hecho, ni el mismo Miyazaki Tsutomu era conocedor de la palabra. ${ }^{38}$

El primero de los tres artículos, "La ciudad está llena de 'otaku", continúa el trabajo de Shirakawa y expone una definición mucho más detallada del mismo estereotipo a través de una observación de los asistentes al ComiKet, aunque incluso aún más peyorativa. Es en este primer texto en que se pueden comprobar las coincidencias con el artículo de Shirakawa, pues Nakamori incide en el párrafo inicial en la falta de capacidad física de estos jóvenes, a la que añade una irónica descripción de su forma de vestir, y describe después el tipo de aficiones que les interesan, dejando claro que van más allá del manga y el anime, y remarcando como característica, del mismo modo que Shirakawa, que tales intereses alcanzan la categoría de fanatismo.

La otra característica de especial relevancia que añade Nakamori en su definición, y que centra el discurso del segundo artículo, titulado “¿Los 'otaku' también se enamoran de gente normal?”, es su masculinidad, o en sus propias palabras, la desaparición de esta. Nakamori señala elementos como la falta de interés por las mujeres reales a favor de una obsesión enfermiza con personajes de anime, o la tendencia al gusto por el lolicon, que años después resultarán clave para relacionar a Miyazaki Tsutomu con el término 'otaku'.

Por último, el tercero de los artículos, titulado "Perdido en la zona otaku", profundiza en el término y en el uso de este, a la vez que enfatiza la característica que considera definitoria de los otaku: el hecho de no tener novia. De hecho, con un tono especialmente peyorativo narra cómo acudió a Free Space, una tienda de dōjinshi situada en el distrito de Shinjuku, en Tokio, donde solían reunirse los otaku, acompañado de su propia novia con la intención de burlarse de ellos. ${ }^{39}$

Es interesante comprobar, sin embargo, que, aunque el motivo principal por el que se reconoce al Estudio de 'otaku' de Nakamori Akio es por relacionar con esta definición el concepto de 'otaku', lo cierto es que el autor apenas dedica una frase a ello, justificando su elección por el hecho ya mencionado de que era un término que los otaku ya utilizaban para llamarse entre ellos, tal vez una muestra del mayor conocimiento de Nakamori sobre estos jóvenes en comparación al expuesto por Shirakawa.

El crítico cultural Ōtsuka Eiji, que era editor de la revista Manga Burikko durante la época de publicación de estos tres ensayos, realizó una dura crítica a los mismos, asegurando que la intencionalidad de Nakamori era situarse por encima de los otaku mediante la creación de una etiqueta discriminativa, para considerarse parte del colectivo de jóvenes conocidos como shinjinrui o 'nueva raza' y ensalzarlos a través de la diferenciación..$^{40}$

Fue precisamente Ōtsuka el encargado de cancelar la columna de Nakamori en Manga Burikko, ya que, como señala Yamanaka Tomomi, el consumidor medio de la revista era, precisamente, aficionado al lolicon del mismo género y franja de edad que los otaku descritos por Nakamori, lo que generó una enorme controversia entre los lectores. ${ }^{41}$

\footnotetext{
Parque situado en Shinjuku.

Nakamori, “'Otaku' no kenkyū - otaku”.

Galbraith y Lamarre. "Otakuology", 363.

Yamanaka, "Birth of "otaku", 38.

Ōtsuka, xx.

Yamanaka. "Birth of 'otaku", 39.
} 
En opinión de Nagata Daisuke, que Nakamori escogiera precisamente a los otaku como objeto de su diferenciación responde, quizá, al hecho de que él mismo fuera un otaku, ya que solo así se explica que tuviera conocimiento, por ejemplo, del uso de 'otaku' como pronombre personal de segunda persona entre los otaku, de sus actividades y costumbres más allá de las que podía presenciar en el Comic Market, o su propia presencia en el ComiKet. ${ }^{42}$ Sin embargo, y a pesar de la evidente intención peyorativa de la definición acuñada por Nakamori, los otaku la asimilaron y continuaron usando la palabra como habían hecho hasta entonces, sin renegar de ella, lo que para Morikawa significa que se estaban auto despreciando, pero que, al mismo tiempo, se estaban reafirmando a sí mismos. La razón parece simple: dado que ya lo estaban usando, era un término que les resultaba familiar y fácil de entender. ${ }^{43}$

\section{Conclusión}

La revisión del texto de Shirakawa ofrece una visión personal y satírica de un momento previo a la acuñación formal del concepto 'otaku', y permite comprobar la existencia de un estereotipo que coincide en uso y forma con la acepción de 'otaku' como sinónimo de nerd. En 1983, Nakamori construyó esa misma etiqueta alrededor de 'otaku', y dibujó una imagen que se asentaría definitivamente en 1989, cuando Miyazaki Tsutomu cometió sus asesinatos.

Por ello, a pesar de que es a raíz del "incidente Miyazaki" cuando esta imagen de 'otaku' se extendería masivamente por la sociedad japonesa, las dos fuentes presentadas en este trabajo son imprescindibles para rastrear los orígenes de su construcción conceptual, y entender de dónde procede una connotación peyorativa y tenebrosa que aún hoy, en Japón, sigue oscureciendo a este colectivo.

\section{Bibliografía}

Ōtsuka, Eiji. "Otaku culture as 'Conversion Literature". En Debating Otaku in Contemporary Japan, editado por Galbraith, Patrick W., Thiam Huat Kam and Björn-Ole Kamm, xiii-xxix. London: Bloomsbury Academic, 2015.

Galbraith, Patrick W., and Thomas Lamarre. "Otakuology: A Dialogue”, Mechademia 5, University of Minnesota Press (2010): 360-374.

Kinsella, Sharon. Adult Manga: Culture and Power in Contemporary Japan Society. Richmond: Curzon Press, 2000.

Miyadai, Shinji, Thomas Lamarre (intro.) and Shion Kono (trad.). "Transformation of Semantics in the History of Japanese Subcultures since 1992", Mechademia 6, University of Minnesota Press (2011): 231-258.

Morikawa, Kaichirō, and Dennis Washburn. “おたく Otaku/Geek”, Working Words: New Approaches to Japanese Studies, University of Berkeley (2012): 1-17.

Nagata, Daisuke. “'Otaku o ronzuru koto’ o meguru hihyōteki genron to shakaigaku to no kyori ni kan shite” (「オタ クを論ずること」をめぐる批評的言論と社会学との距離に関して). Comunicación presentada en Nihon masu komyunikēshon gakkai - 2016 nendo shunki kenkyü happyōkai (日本マス・コミュニケーション学会・2016年度 春季研究発表会), Universidad de Tsukuba, 18-19 de junio de 2016.

Nakamori, Akio. “'Otaku' no kenkyū - (1) Machi ni wa 'otaku' ga ippai” (『おたく』の研究 - (1) 街には『おた く』がいっぱい), Manga Burikko (漫画ブリッコ), nº junio (1983): 200-201.

Nakamori, Akio. “'Otaku' no kenkyū - (2) ‘Otaku’ mo hitonami ni koi o suru”(『おたく』の研究 - (2) 『おたく』 も人並みに恋をする?), Manga Burikko (漫画ブリッコ), no julio (1983): 89-100.

Nakamori, Akio. “'Otaku’ no kenkyū - Otaku chitai ni mayoi konda de” (『おたく』の研究 - おたく地带に迷いこん だで), Manga Burikko (漫画ブリッコ), no agosto (1983), consultado el 18-04-2021, http://www.burikko.net/people/ otaku03.html

Okada, Toshio. Otakugaku nyūmon (オタク学入門). Tokio: Ohta Publishing Company, 1996.

Shirakawa, Shōmei. "Darakukun no yoi ko kyōshitsu koyoi mo kamonoha shiru dai 1 kai: shin'nyūsei no tame no hissatsu yoi ko kokoroe shūtoku kōza” (「ダラク君のよい子教室今宵もカモ)八しる第 1 回 : 新入生のための必殺よ い子心得習得講座」), Fanrōdo dai 2-kan dai 2-gō (ふあんろーど第 2 巻第 2 号) (1981), pp. 68-71.

Yamanaka, Tomomi. "Birth of 'otaku"'. En Debating Otaku in Contemporary Japan, editado por Galbraith, Patrick W., Thiam Huat Kam and Björn-Ole Kamm, 35-50. London: Bloomsbury Academic, 2015.

\footnotetext{
Nagata, “'Otaku o ronzuru koto' o", 2

43 Morikawa y Washburn, “おたく/Otaku/Geek”, 7-8.
} 